\title{
STUDY OF VITAMIN D LEVELS IN PULMONARY TUBERCULOSIS PATIENTS AT A TERTIARY CARE HOSPITAL
}

\author{
Rohit Vasant Deshpande ${ }^{1}$, Bharat Sing Rathod ${ }^{2}$, Parag Nemant Rahtekar ${ }^{3}$, Amol Dandurang Bhore $^{4}$, Swati Harish Sharma ${ }^{5}$, \\ Hitesh Lotan Mahale 6
}

\begin{abstract}
${ }^{1}$ Associate Professor, Department of General Medicine, Grant Government Medical College and Sir J. J. Group of Hospitals, Mumbai. ${ }^{2}$ Associate Professor, Department of General Medicine, Grant Government Medical College and Sir J. J. Group of Hospitals, Mumbai. ${ }^{3}$ Ex-Resident, Department of General Medicine, Grant Government Medical College and Sir J. J. Group of Hospitals, Mumbai. ${ }^{4}$ Lecturer, Department of General Medicine, Grant Government Medical College and Sir J. J. Group of Hospitals, Mumbai. ${ }_{5}^{5}$ Senior Resident, Department of General Medicine, Grant Government Medical College and Sir J. J. Group of Hospitals, Mumbai. ${ }^{6}$ Ex-Resident, Department of General Medicine, Grant Government Medical College and Sir J. J. Group of Hospitals, Mumbai.
\end{abstract}

\section{BACKGROUND}

ABSTRACT

Currently available literature highlights association of hypovitaminosis D with chronic diseases such as diabetes mellitus and systemic hypertension, but there are very few studies on role of vitamin D in pulmonary tuberculosis (PTB) in our population.

\section{MATERIALS AND METHODS}

Vitamin D levels in 180 cases of newly diagnosed active pulmonary tuberculosis (Both sputum positive and sputum negative) and 180 age and gender matched healthy controls were estimated. 25 Hydroxy vitamin D3 levels were estimated by sensitive fully automated Chemiluminescent Immunoassay (CLIA) technique. Vitamin D3 levels were categorised as sufficient, insufficient and deficient. Patients were followed for six months for final outcome (Tuberculosis cured/not cured).

\section{RESULTS}

Out of 180 cases, 95 (52.78\%) were sputum positive and the remaining 85 (47.22\%) were sputum negative. Mean vitamin D levels were significantly low in cases $(12.23 \pm 5.99 \mathrm{ng} / \mathrm{mL})$ as compared to controls $(18.7 \pm 10.19 \mathrm{ng} / \mathrm{mL})(\mathrm{p}$ value $<0.001)$. Among the 180 cases, 158 (87.78\%) had vitamin D deficiency, 18 (10\%) had vitamin D insufficiency; whereas among controls, 105 (58.33\%) had vitamin D deficiency, 46 (25.56\%) had vitamin D insufficiency. The prevalence of vitamin D deficiency and vitamin D insufficiency was higher among cases compared to controls ( $p$-value $<0.05$ ).

\section{CONCLUSION}

There is significant deficiency of Vitamin D in patients with PTB. More prospective designed studies are needed to firmly establish the direction of association between PTB and vitamin D deficiency (VDD).

\section{KEYWORDS}

Vitamin D Deficiency, Pulmonary Tuberculosis.

HOW TO CITE THIS ARTICLE: Deshpande RV, Rathod BS, Rahtekar PN, et al. Study of vitamin D levels in pulmonary tuberculosis patients at a tertiary care hospital. J. Evolution Med. Dent. Sci. 2017;6(44):3424-3426, DOI: 10.14260/Jemds/2017/742

\section{BACKGROUND}

Though vitamin $\mathrm{D}$ belongs to the class of vitamins, it is unique because it is also synthesised in the body and functions as a hormone. Besides having a crucial role in calcium homeostasis and bone mineral metabolism, it is known to be involved in biological functions like cell differentiation, inhibition of cell growth and immunomodulation.1,2,3 Vitamin D modulates monocyte-macrophage activity in the body and plays a role in human innate immunity to certain infectious agents. ${ }^{4}$ This role may be important in the body's defence against tuberculosis, in which attack of macrophages is a key step in pathogenesis. Vitamin D acts by binding to nuclear receptors on target cells. Therefore, both low levels of the vitamin and abnormalities in receptor structure and function

Financial or Other, Competing Interest: None.

Submission 19-04-2017, Peer Review 19-05-2017,

Acceptance 25-05-2017, Published 01-06-2017.

Corresponding Author:

Dr. Rohit Vasant Deshpande,

Kanti Apartments,

A-Wing-1104, Near Mount Mary Church,

Bandra West-400050, Maharashtra, India.

E-mail: coolrohit258@gmail.com

DOI: $10.14260 /$ jemds $/ 2017 / 742$ may result in impairments in host immunity to the tubercle bacillus. ${ }^{5}$ Being a tropical country it was firmly believed that vitamin D deficiency did not exist in India. Following an original observation made in 1993 in a 14-year-old boy with skeletal tuberculosis in whom there was documented vitamin D deficiency, it was hypothesised that it could be a cause rather than the effect. ${ }^{6}$ Tuberculosis is a major global health problem and often coincides with nutritional deficiency. In fact, vitamin D deficiency has been reported among tuberculosis patients, and vitamin D receptor polymorphisms are associated with susceptibility to Mycobacterium tuberculosis. ${ }^{7}$ High doses of vitamin D were widely used to treat TB patients in the pre-antibiotic era. ${ }^{8}$ The present study was undertaken to study vitamin D levels in newly diagnosed cases of PTB in Indian scenario.

\section{MATERIALS AND METHODS}

This case control study was carried out at tertiary care teaching hospital during the period of October 2012 to July 19,2014 . Total 180 cases of newly diagnosed PTB (by sputum microscopy and chest x-ray) were included. 180 age and gender matched controls were recruited from healthy visitors and relatives of patients. Both cases and controls were subjected for clinical history with particular reference to 
symptoms of hypovitaminosis D such as frequent musculoskeletal pain and proximal muscle weakness, physical examination and vitamin D3 level using fully automated Chemiluminescent Immunoassay (CLIA) technique. Routine necessary blood investigations of cases i.e. complete blood count, random blood sugar, renal function test (blood urea, serum creatinine), serum calcium, liver function test (SGOT, SGPT, serum bilirubin, serum albumin) were done. The blood samples of patients for estimation of vitamin $\mathrm{D}$ were taken before starting anti-tuberculous treatment. PTB patients who were otherwise prone for vitamin D deficiency like malabsorption, liver or renal disorders, diabetes mellitus, systemic hypertension and those on drugs which can reduce vitamin D levels or antagonise its actions were excluded from this study. Those who were predisposed to develop tuberculosis due to other obvious causes also were excluded (HIV infection, diabetes mellitus, on immunosuppressive therapy, severe protein energy malnutrition). Patients were followed up for 6 months for final outcome of pulmonary tuberculosis (i.e. cured or not cured). Patients who completed 6 months of anti-Koch's treatment (AKT) and were sputum negative and symptom free were considered "cured". Whereas patients who had treatment failure (i.e. sputum positive even after 2 months, 5 months of AKT) and those who died were considered "not cured". Participants not giving valid written consent were excluded from this study. The study was approved by institutional ethics committee. The previous published studies have documented 70 to $90 \%$ vitamin D deficiency in general population in India. ${ }^{9}$ The sample size for present 1:1 matched case-control study was calculated using Odds ratio of 2 , alpha error of 0.05 , power of study as $80 \%$ and percentage exposed among controls as $70 \%$, thus justifying our sample size of 180 cases.

\section{Statistical Analysis}

Data was analysed using the Microsoft excel program. Data was compared using student's t-test for continuous variables and chi square test for categorical variables as appropriate. Pvalue $\leq 0.05$ was considered as significant.

\section{RESULTS}

The mean age of cases $(n=180)$ in our study was $38.13 \pm$ 16.24 years. Majority of the cases were young i.e. 85 $(47.22 \%)$ from $21-40$ years age group. Male $(n=105)$ to female $(n=75)$ ratio was 1.40:1. Majority of the cases had symptoms of fever (91.67\%), cough with expectoration (91.11\%) and loss of appetite (70\%). Less common symptoms were chest pain, haemoptysis, breathlessness and weight loss. Among cases, 95 (52.78\%) were sputum positive and the remaining 85 (47.22\%) were sputum negative. Mean vitamin D levels were significantly low in cases $(12.23 \pm 5.99$ $\mathrm{ng} / \mathrm{mL})$ as compared to controls $(18.7 \pm 10.19 \mathrm{ng} / \mathrm{mL})(\mathrm{p}$ value $<0.001)$. Mean vitamin D levels were significantly lower in sputum-positive cases $(10.90 \pm 6.82 \mathrm{ng} / \mathrm{mL})$ as compared to sputum-negative cases $(13.74 \pm 6.08 \mathrm{ng} / \mathrm{mL}$ ) (p value < $0.05)$. According to serum vitamin D levels, cases and controls were divided into normal, insufficiency and deficiency groups (Table 1). Symptoms of hypovitaminosis D were present only in $21.59 \%$ of the cases with hypovitaminosis D (38 out of 176 ) as compared to $3.97 \%$ of controls with hypovitaminosis D (6 out of 151). There was no significant difference in vitamin D level in clinical outcome. (Table 2).

\begin{tabular}{|c|c|c|c|c|}
\hline $\begin{array}{c}\text { Sr. } \\
\text { No. }\end{array}$ & $\begin{array}{c}\text { Serum Vitamin } \\
\text { D Level (ng/mL) }\end{array}$ & $\begin{array}{c}\text { Cases } \\
(\mathbf{n = 1 8 0})\end{array}$ & $\begin{array}{c}\text { Controls } \\
(\mathbf{n = 1 8 0})\end{array}$ & $\begin{array}{c}\text { P- } \\
\text { value }\end{array}$ \\
\hline 1. & Normal $(\geq 30 \mathrm{ng} / \mathrm{mL})$ & $4(2.22 \%)$ & $29(16.11 \%)$ & 0.009 \\
\hline 2. & $\begin{array}{c}\text { Insufficiency } \\
(\geq 20 \text { and }<30 \mathrm{ng} / \mathrm{mL})\end{array}$ & $18(10 \%)$ & $46(25.56 \%)$ & 0.020 \\
\hline 3. & $\begin{array}{c}\text { Deficiency } \\
(<20 \mathrm{ng} / \mathrm{mL})\end{array}$ & $\begin{array}{c}158 \\
(87.78 \%)\end{array}$ & $\begin{array}{c}105 \\
(58.33 \%)\end{array}$ & 0.003 \\
\hline \multicolumn{5}{|c|}{ Table 1. Vitami-square - 41.87, p < $<0.001$} \\
\hline
\end{tabular}

\begin{tabular}{|c|c|c|c|}
\hline $\begin{array}{c}\text { Clinical Outcome } \\
\text { of Cases }\end{array}$ & Cured & Not Cured & P-value \\
\hline $\begin{array}{c}\text { Mean vitamin } \\
\text { D levels (ng/mL) }\end{array}$ & $12.33 \pm 5.95$ & $9.33 \pm 6.98$ & 0.343 \\
\hline
\end{tabular}

Table 2. Comparison of Vitamin D Level Among Cases According to Clinical Outcome

\section{DISCUSSION}

In this study, we had observed statistically significant association between PTB and hypovitaminosis. D. Kelechi EN et $\mathrm{al}^{10}$ in their meta-analysis had reviewed seven primary studies and found that patients with tuberculosis had lower serum levels of vitamin D than healthy controls matched on sex, age, ethnicity, diet and geographical location. The pooled effect size in random effects meta-analysis was 0.68 with 95\% CI 0.43-0.93. This 'medium to large' effect represents a probability of $70 \%$ that a healthy individual would have higher serum vitamin D level than an individual with tuberculosis if both were chosen at random from a population. PK Sasidharan et al ${ }^{11}$ in his study from Kerala and Najeeha Talat et al $^{12}$ from Pakistan also found significant vitamin D deficiency in tuberculosis patients as compared to healthy controls. Another study from India by Rathored et $\mathrm{al}^{7}$ concluded that vitamin D receptor gene polymorphism and hypovitaminosis D may predispose to MDR-TB. They also found that vitamin D level was significantly lower in MDR-TB as compared to drug-sensitive TB and disease severity, time to sputum smear and culture conversion were inversely correlated with vitamin D levels. In our study, vitamin D was significantly lower in sputum-positive cases as compared to sputum-negative cases and as the sputum smear grade of AFB increased the vitamin D levels decreased further.

We also observed that asymptomatic hypovitaminosis D is highly prevalent in apparently healthy individuals. Several published studies $13,14,15$ had confirmed the possibility of wide spread deficiency of vitamin D in India, in spite of being a sunny country. The major reasons for low vitamin D in our country are 1) poor dietary intake of vitamin D and not decreased sun light exposure, 2) reduced cutaneous biosynthesis of vitamin D could be due to the increased melanin in skin, 3) poor intake of vegetables, which is a very common issue in most people of our country, and the resultant magnesium deficiency might lead to reduced Parathyroid hormone (PTH) secretion and the consequent reduction of 1-hydroxylation of vitamin D. 16

There is scarcity of data regarding effect of outcome of PTB in hypovitaminosis D patients from our country. ${ }^{17}$ Though sample size was small, we did not find any significant difference in vitamin D level between cured PTB cases and non-cured PTB cases.

Vitamin D has been attributed an important role in host immune defence against Mycobacterium tuberculosis. ${ }^{18}$ It has been shown by Liu et al 19 that vitamin D supplementation 
results in increased expression of anti-microbial peptide 'cathelicidin' in the macrophage culture, which could result in killing of the intracellular Mycobacterium tuberculosis. This is a potential mechanism which could logically explain role of vitamin $D$ in enhancing immunity in patients with tuberculosis.

There is a long history of using vitamin D to treat tuberculosis with some apparent success. Finsen, in his Nobel prize winning discovery, successfully used UVB rays to treat the cutaneous form of tuberculosis. ${ }^{20}$ Dowling and Prosser Thomas reported the treatment of tuberculosis with oral vitamin D in 1946.21 Vitamin D supplementation is being tried as adjuvant to chemotherapy in PTB, enhancing antimicrobial response and accelerating clearance of bacilli in some patients. ${ }^{22,23}$

We have some limitation of our study. We are unable to do detailed dietary assessment of the intake of vitamin D in cases and controls. We have not excluded smoking persons from this study. Smoking, being a risk factor for PTB and theoretically can decrease calcium absorption thereby altering vitamin D level, can be a confounding factor. ${ }^{24,25}$ Being a cross sectional study, the temporality between PTB and vitamin D deficiency could not be established.

Implication of this study is that all PTB patients should be screened for vitamin D deficiency.

\section{CONCLUSION}

There is significant deficiency of Vitamin D in patients with PTB. Asymptomatic vitamin D deficiency is common in apparently healthy persons. Larger prospective studies are necessary to firmly establish the direction of the association between vitamin D deficiency and PTB. Randomised control trials are needed for determining role of vitamin D supplementation in PTB treatment.

\section{ACKNOWLEDGEMENTS}

Dr. N. N. Ramraje, Professor and Head of the Department, Dept. of Chest and Tuberculosis, Grant Government Medical College, Mumbai.

\section{REFERENCES}

[1] Denis M. Killing of mycobacterium tuberculosis within human monocytes, activation by cytokines and calcitriol. Clin Exp Immunol 1991;84(2):200-6.

[2] Abu-Amer Y, Bar-Shavit Z. Impaired bone marrow derived macrophage differentiation in vitamin $D$ deficiency. Cell Immunol 1993;151(2):356-68.

[3] Stechschulte SA, Kirsner RS, Federman DG. Vitamin D: bone and beyond, rationale and recommendations for supplementation. The American Journal of Medicine 2009;122(9):793-802.

[4] Kreutz M, Andreesen R. Induction of human monocyte to macrophage maturation in vitro by 1,25 dihydroxyvitamin D3. Blood 1990;76(12):2457-61.

[5] Wilkinson RJ, Llewelyn M, Toossi Z, et al. Influence of vitamin $\mathrm{D}$ deficiency and vitamin $\mathrm{D}$ receptor polymorphisms on tuberculosis among Gujarati Asians in west London: a case-control study. Lancet 2000;355(9204):618-21.

[6] Sasidharan PK, Rajeev E, Vijayakumari V. Tuberculous osteomyelitis and vitamin D deficiency. Journal of Calicut Orthopedic Association 2004;2(1).
[7] Rathored J, Sharma SK, Singh B, et al. Risk and outcome of multidrug-resistant tuberculosis: vitamin D receptor polymorphisms and serum 25(OH)D. Int J Tuberc Lung Dis 2012;16(11):1522-8.

[8] Grad R. Cod and the consumptive: a brief history of cod-liver oil in the treatment of pulmonary tuberculosis. Pharm Hist 2004;46(3):106-20.

[9] Schoor VNM, Lips P. Worldwide vitamin D status. Best Pract Res Clin Endocrinol Metab 2011;25(4):671-80.

[10] Kelechi EN, Clarke A. Low serum vitamin D levels and tuberculosis: a systematic review and meta-analysis. Int J Epidemiol 2008;37(1):113-9.

[11] Sasidharan PK, Rajeev E, Vijayakumari V. Tuberculosis and vitamin D deficiency. Journal of Association of Physicians of India 2002;50:554-8.

[12] Najeeha T, Perry S, Parsonnet J, et al. Vitamin D deficiency and tuberculosis progression. Emerg Infect Dis 2010;16(5):853-5.

[13] Goswami R, Gupta N, Goswami D, et al. Prevalence and significance of low 25-hydroxyvitamin D concentration in healthy subjects in Delhi. Am J Clin Nutr 2000;72(2):472-5.

[14] Marwaha RK, Tandon N, Reddy DR, et al. Vitamin D and bone mineral density status of healthy schoolchildren in northern India. Am J Clin Nutr 2005;82(2):477-82.

[15] Baidya A, Chowdhury S, Mukhopadhyay S, et al. Profile of vitamin $\mathrm{D}$ in a cohort of physicians and diabetologists in Kolkata. Indian J Endocrinol Metab 2012;16(Suppl 2):S416-7.

[16] Holick MF. Vitamin D deficiency. N Engl J Med 2007;357(3):266-81.

[17] Nursyam EW, Amin Z, Rumende CM. The effect of vitamin $\mathrm{D}$ as supplementary treatment in patients with moderately advanced pulmonary tuberculous lesion. Acta Med Indones 2006;38(1):3-5.

[18] Rockett KA, Brookes R, Udalova I, et al. 1,25Dihydroxyvitamin D3 induces nitric oxide synthase and suppresses growth of mycobacterium tuberculosis in human macrophage-like cell line. Infect Immun 1998;66(11):5314-21.

[19] Liu PT, Stenger S, Li H, et al. Toll-like receptor triggering of a vitamin D-mediated human antimicrobial response. Science 2006;311(5768):1770-3.

[20] http://nobelprize.org/nobel_prizes/medicine/laureat es/1903/finsen-bio.html.

[21] Dowling GB, Thomas PEW. Treatment of lupus vulgaris with Calciferol. Lancet 1946;1(6408):919-22.

[22] Essam GH, Enas EM, Baessa AI, et al. The role of supplementary vitamin D in treatment course of pulmonary tuberculosis. Egyptian J of Chest Diseases and Tuberculosis 2016;65(3):629-35.

[23] Xia J, Shi L, Zhao L, et al. Impact of vitamin D supplementation on the outcome of tuberculosis treatment: a systematic review and meta-analysis of randomized controlled trials. Chin Med J Engl 2014;127(17):3127-34.

[24] Underner M, Perriot J. Smoking and tuberculosis. Presse Med 2012;41(12 Pt 1):1171-80.

[25] Brot C, Jorgensen NR, Sorensen OH. The influence of smoking on vitamin D status and calcium metabolism. Eur J Clin Nutr 1999;53(12):920-6. 